\title{
PEMBERDAYAAN MASYARAKAT MELALUI PENGEMBANGAN PRODUK KOPI KARE DAN WISATA ALAM BERBASIS EKOWISATA DI DESA KARE KECAMATAN KARE KABUPATEN MADIUN.
}

\author{
Liana Vivin Wihartanti ${ }^{1}$, Farida Styaningrum², Galih Chandra Noegraha ${ }^{3}$ \\ 1,2,3 Universitas PGRI Madiun \\ Email: lianavivin@unipma.ac.id
}

\begin{abstract}
Kare is a village located on the slopes of Wilis Mountains. The charm of natural tourism that is still natural in Kare is still not managed optimally by the community. The object in this Community Service activity is coffee plantations. The results of local coffee in Kare are a potential resource, but the marketing has not yet reached the Madiun Regency area. The Community Service activity aims to improve the marketing of kare coffee and make the Tambak Lare coffee plantation a tourist destination based on ecotourism. The results of the Community Service show that the marketing of kare coffee has expanded not only around Kare but has reached the Madiun Regency, such as Madiun City, Ngawi Regency, Magetan Regency, to outside the provinces such as Klaten Regency and Sragen Regency. The Tambak Lare coffee plantation located in Kare Village, Kare Subdistrict, Madiun Regency has begun to be initiated to become an ecotourism-based nature tourism, so that there are already people outside Kare who visit these tourist sites.
\end{abstract}

Keywords: Kare Coffee, Nature Tourism, Ecotourism

\begin{abstract}
Abstrak. Desa kare merupakan sebuah desa yang terletak di lereng pegunungan wilis. Pesona wisata alam yang masih natural yang terdapat di desa kare masih belum di kelola secara maksimal oleh masyarakat setempet. Objek dalam kegiatan Pengabdian Masyarakat ini adalah perkebunan kopi. Hasil kopi lokal di Desa Kare merupakan sumberdaya yang potensial, namun pemasaran belum sampai keluar daerah Kabupaten Madiun. Kegiatan Pengabdian Masyarakat ini bertujuan untuk meningkatkan pemasaran kopi kare serta menjadikan perkebunan kopi Tambak Lare menjadi tempat wisata yang berbasis ekowisata. Hasil kegiatan Pengabdian Masyarakat menunjukkan bahwa pemasaran kopi kare sudah meluas tidak hanya di sekitar Desa Kare tetapi sudah sampai keluar Kabupaten Madiun, seperti Kota Madiun, Kabupaten Ngawi, Kabupaten Magetan, hingga diluar provinsi seperti di Kabupaten Klaten dan Kabupaten Sragen. Perkebunan kopi Tambak Lare yang terletak di Desa Kare, Kecamatan Kare, Kabupaten Madiun sudah mulai dirintis untuk menjadi wisata alam berbasis ekowisata, sehingga sudah ada masyarakat luar Desa Kare yang berkunjung ketempat wisata tersebut.
\end{abstract}

Kata kunci : Kopi Kare, Wisata Alam, Ekowisata

\section{PENDAHULUAN}

Perkembangan wisata makin kian berkembang pesat, perkembangan dunia wisata telah mengalami berbagai perubahan baik perubahan pola, bentuk, dan sifat kegiatan, dorongan orang untuk melakukan perjalanan, cara berpikir, maupun sifat perkembangan itu sendiri (Sidiq \& Prihatmaji, 2017). Di negara maju wisata sudah bukan hal yang baru lagi bahkan orang melakukan suatu perjalanan merupakan kebutuhan hidup suatu manusia. Suatu daerah wisata mempunyai kemampuan tertentu untuk menerima wisatawan, yang biasa disebut dengan daya dukung lingkungan (Sari \& Taher, 2017). Daya dukung lingkungan di bidang wisata dapat dinyatakan dalam jumlah wisatawan per satuan luas per satuan waktu. Wisata yang dimaksud tidak hanya wisata alam saja, melainkan wisata budaya, wisata kuliner dan wisata kebun warga.

Indonesia merupakan negara yang memiliki potensi wisata yang sangat luar biasa khususnya wisata alam dan budaya. Hampir setiap daerah di Indonesia memiliki ciri tersendiri dalam keindahan dan keelokan alam serta keberagaman budayanya. Industri pariwisata di Indonesia sendiri mampu meningkatkan 
pendapatan setiap daerah, sehingga masyarakatnya menjadi lebih makmur. Minimnya pengetahuan tentang pengelolaan potensi daerah membuat daerah tersebut kurang terekspos baik di dalam negeri maupun di mancanegara.

Wisata yang ada di desa tidak kalah menarik dengan wisata di kota, justru wisata di desa sekarang menjadi tujuan bagi para wisatawan untuk berlibur. Kare merupakan salah satu desa di daerah madiun yang memiliki potensi sumberdaya alam begitu melimpah. Potensi saat ini yang sangat menonjol dalam bidang pertanian dan perkebunan yang meliputi pertanian padi, kedelai, palawija, perkebunan kakao, kopi, durian dan produk hasil peternakan berupa susu. Kopi dan kakao merupakan aset penting yang ingin ditonjolkan di daerah tersebut.

Selain produk kopi, juga terdapat perkebunan kopi Tambak Lare yang terletak di Desa Kare, Kecamatan Kare, Kabupaten Madiun. Tambak Lare merupakan sebuah aset daerah yang potensial untuk dijadikan sebagai tempat wisata. Potensi kebun kopi di desa Kare dapat dijadikan sebagai pemasaran yang sangat menjanjikan, dengan mengembangkan lahan pekebunan menjadi salah satu area Ekowisata (Yuhana \& Nurhikmawati, 2017). Kawasan perkebunan Tambak Lare memiliki lahan yang sangat luas serta telah ada beberapa fasilitas umum seperti tempat duduk, kamar mandi umum dan warung kopi sederhana.

Prasyarat utama agar aset yang cukup berharga tersebut bisa menjadi sebuah komoditas daerah adalah dikelolanya potensi daerah tersebut dengan baik sesuai standar minimal industri pariwisata (Arifin \& Ariyanto, 2018). Potensi kebun kopi di desa Kare jika dikelola dengan baik dapat menjadi salah satu area Ekowisata yang dapat menambah penghasilan masyarakat sekitar dan menambah pendapatan asli daerah. Adanya area ekowisata diharapkan dapat meningkatkan pengembangan kopi kare sehingga potensi kopi di daerah tersebut dapat di kenal lebih luas dan menjadi icon wisata di desa Kare. Keberadaan Ekowisata dapat mengembangkan kopi kare melalui sektor pariwisata.

Berdasarkan uraian di atas, penggagas memiliki gagasan untuk mengembangkan potensi daerah tersebut menjadi daerah wisata alam berbasis ekowisata sebagai langkah strategis dalam memperkenalkan potensi wisata di Desa Kare, Kecamatan Kare, Kabupaten Madiun agar lebih dikenal oleh masyarakat luas serta mendukung dalam perluasan pemasaran kopi kare.

\section{METODE PELAKSANAAN}

Metode yang digunakan dalam program kegiatan pengabdaian kepada masyarakat ini adalahSurvei tempat-tempat yang akan digunakan untuk program. Kegiatan abdimas ini merupakan program yang yang melibatkan dosen dan mahasiswa serta masyarakat setempat yang menjadi lokasi dari kegiatan pengabdian masyarakat tersebut. Pengabdian masyarakat ini terdiri dari dua dosen dan 12 mahasiswa yang membantu dalam program yang akan dilaksanakan. Program tersebut dilaksanakan di suweru, desa kare, kecamatan kare kabu paten Madiun. Survei lokasi serta survei program merupakan strategi yang dilaksanakan untuk mengetahui sejauh mana program masyarakat dalam mengelola perkebunan kopi serta respon dari masyarakat sekitar mengenai strategi pemasaran produksi kopi yang ada di dusun suweru yang dikelola oleh kelompok tani mugi lestari serta perkebunan kopi tambak lare yang di kelola oleh kelompok tani giri willis.

Koordinasi dengan berbagai pihak antara lain adalah kelompok tani "Mugi Lestari", perkumpulan "Giri Wilis", ketua RT, Perangkat Desa, serta masyarakat setempat. Pembuatan desain kemasan untuk produk kopi sachet dan strategi pemasarannya yang awalnya hanya kemasan kopi bubuk ukuran 100gr saja. Kemudian untuk lebih praktis dan efesien serta mudah dibawa akhirnya mencoba untuk membuat kemasan yang sachet,dalam hal ini kami tidak mengubah logo serta icon dari kopi kare dikarenakan kopi kare sudah memiliki merk dagang yang didaftarkan ke dinas perdagangan kabupaten madiun. Kami hanya sekedar membantu peking dalam kemasan yang efisien serta lebih praktis. Revitalisasi area wisata perkebunan kopi Tambak Lare meliputi pembuatan dua buah spot foto, renovasi gapura selamat datang, pembersihan lahan perkebunan, renovasi untuk coffe Shop sederhana. Opening wahana wisata tambak lare dan kedung ketuban. 


\section{HASIL DAN PEMBAHASAN}

Hasil dari kegiatan yang telah dilaksanakan adalah terciptanya kerjasama yang baik dengan berbagai pihak antara lain adalah kelompok tani "Mugi Lestari”, perkumpulan "Giri Wilis", ketua RT, serta masayarakat setempat. adanya kerjasama tersebut dapat tercipta produk kopi kemasan sachet dengan berat 12 gram serta terwujudnya rintisan Ekowisata Tambak Lare sebagai cikal bakal Ekowisata Kopi di Desa Kare, Kecamatan Kare, Kabupaten Madiun.

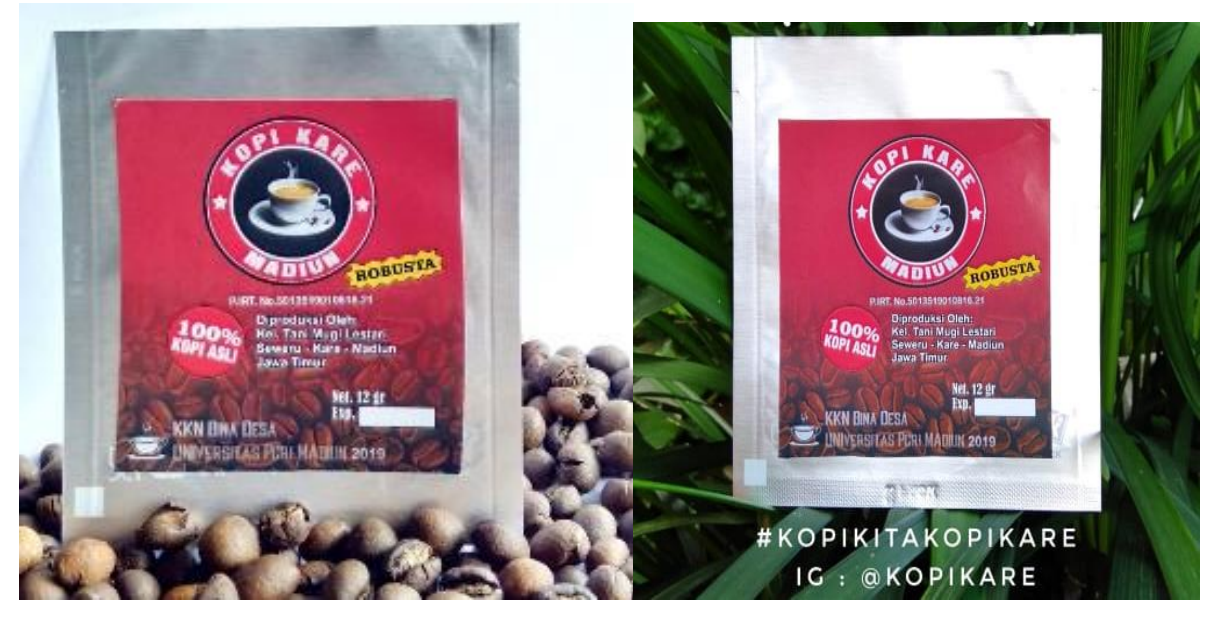

Gambar.1 Kopi sachet

Kemasan untuk kopi dibuat sederhana tetapi tetap terjaga untuk kualitas kopinya dikarenakan kemasan ini kedap udara sehingga apabila disajikan dalam bentuk minuman masih khas rasanya.

Ekowisata tambak lare merupakan sebuah perkebuanan kopi yang dimana perkebuan tersebut sudah ada tetapi masyarakat berlum maksimal untuk mengelolanya serta promosi di media social yang masih minim. Sehingga antusias masyarakat sekitar untuk berkunjungpun masih tergolong sangat kurang, hal ini terlihat dari sedikitnya pengunjung yang datang ke lokasi tambak lare dan kedung ketuban. pengumpulan data dan informasi yang didapat dari masyarakat setempat serta dari kelompok tani maka dari situlah program pengamdian masyarakat kami buat untuk membatu dalam berbenah lokasi wisata sehingga harapannya adalah dengan meningkatnya masyarakat yang datang ke wahana wisata tambak lare dan kedung ketuban tersebut diharapkan dapat meningkatkan perekonomian masyarakat setempat, oleh karena itu pengambian masyarakat yang kami buat adalah membuat spot foto dengan background nuansa alam yang disesuaikan dengan budaya lokal masyarakat kare. Sehingga terkesan natural serta menjunjung tinggi budaya setempat.

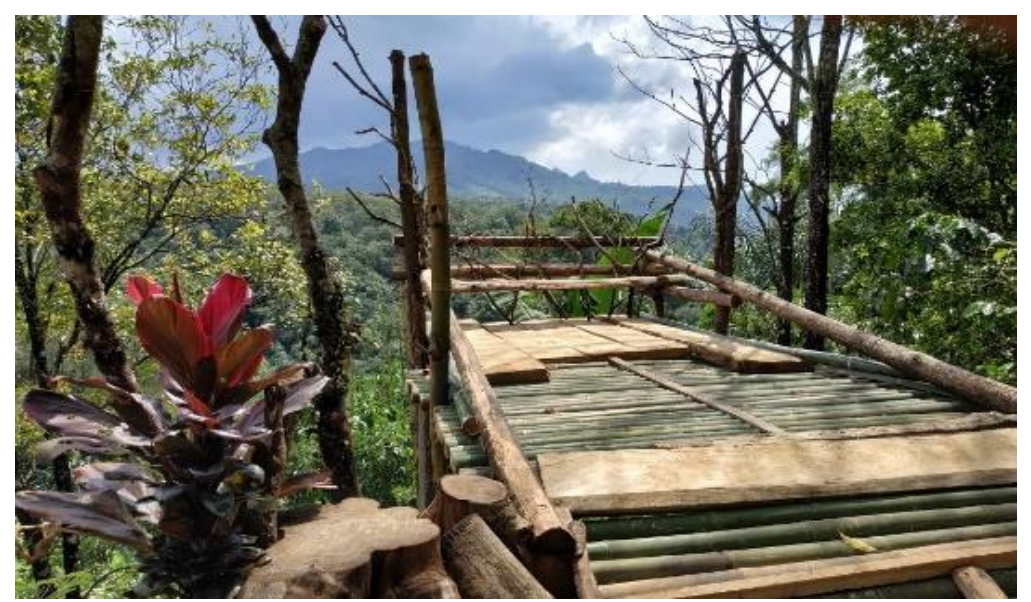

Gambar2. Spot foto 1 


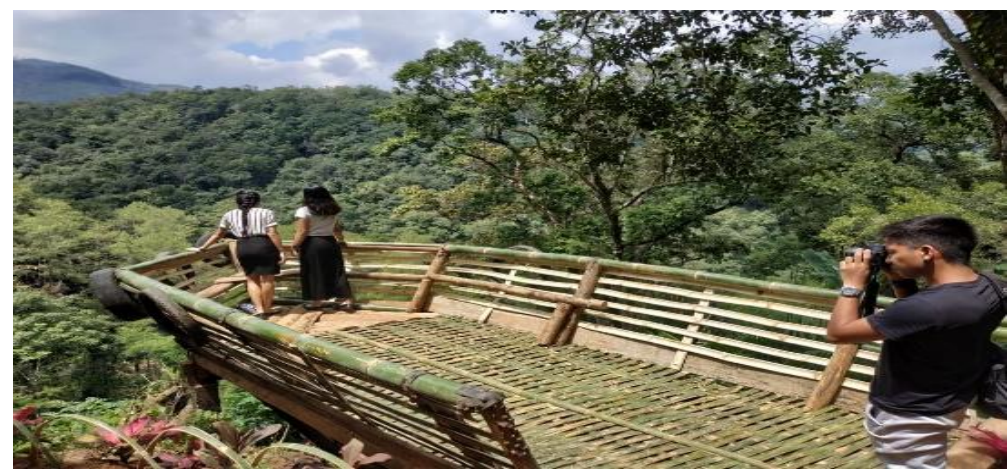

Gambar 2.Spot foto 2

Nuansa spot foto yang dibuat merupakan kerjasama dengan masyarakat setempat yang bertemakan kondisi alam yang ada di desa kare ini terlihat dari pembuatan spot yang menggunakan bambu serta kayu yang memang itu merupakan hasil dari perkebunan yang ada di desa kare.

Tujuan dari pembuatan spot foto tersebut diharapkan akan menambah pengunjung yang datang sehingga warga setempat dapat memanfaatkan peluang wisata tersebut untuk menambah perekonomian warga setempat

\section{SIMPULAN DAN SARAN}

Berdasarkan hasil kegiatan, pengamatan, maupun pelaksanaan kegiatan Pengabdian Masyarakat di Desa Kare Kecamatan Kare, Kabupaten Madiun dapat disimpulkan sebagai berikut:

Pemasaran kopi kare sudah meluas tidak hanya di sekitar Desa Kare tetapi sudah sampai ke Luar Kabupaten Madiun, seperti Kota Madiun, Kabupaten Ngawi, Kabupaten Magetan, hingga diluar provinsi seperti di Kabupaten Klaten dan Kabupaten Sragen Perkebunan Kopi Tambak Lare yang terletak di Desa Kare, Kecamatan Kare, Kabupaten Madiun sudah mulai dirintis untuk menjadi wisata alam berbasis ekowisata, sehingga sudah ada masyarakat luar Desa Kare yang berkunjung ke tempat wisata tersebut.

Saran yang dapat disampaikan untuk keberlanjutan kegiatan Pengabdian Masyarakat sebagai berikut:

Pembuatan web sebagai pendukung dalam pemasaran kopi kare secara online sehingga dapat memperluas pangsa pasar. Pembangunan tempat produksi kopi kare di daerah Tambak Lare untuk mendukung perkembangan wisata alam Tambak Lare yang berbasis ekowisata.

\section{UCAPAN TERIMAKASIH}

Kegiatan Pengabdian Masyarakat ini dapat berjalan lancar karena mendapat bantuan dan dukungan dari berbagai pihak. Oleh karena itu kami ucapkan terima kasih kepada: 1) Universitas PGRI Madiun yang sudah memberikan ijin, sarana dan fasilitas kepada kami, 2) Ketua LPPM Universitas PGRI Madiun

3) Semua mahasiswa KKN Universitas PGRI Madiun Kelompok Kopi di Desa Kare yaitu Lely, Giska, Annida, Dimas, Padma, Aan, Nunik, Sherly, Taufik, Annisa, dan Muti., 4) Kelompok tani "Mugi Lestari" dan kelompok tani "Giri Willis" di Desa Kare yang memberikan tempat untuk kami dalam menimba ilmu dan memberikan kami banyak pengalaman.

\section{DAFTAR PUSTAKA}

Arifin, M., \& Ariyanto. (2018). Desa Penghasil Kopi Untuk Meningkatkan Ekonomi Masyarakat Di Desa Damarwulan Kecamatan Keling Kabupaten Jepara. Jurnal ABDIMAS Unmer Malang, 3(1), 1931.

Sari, I. P., \& Taher, A. (2017). Pengembangan Agrowisata Kebun Kopi Pada Masyarakat Kampung Jamur Ujung Kecamatan Wih Pesam Kabupaten Bener Meriah. Jurnal Ilmiah Mahasiswa FISIP Unsyiah, 3(1).

Sidiq, S., \& Prihatmaji, Y. P. (2017). KKN-PPM Pemberdayaan Melalui Pengembangan Desa Wisata Nglingo, Kulon Progo, Daerah Istimewa Yogyakarta. Prosiding SNaPP2017 Sosial, Ekonomi, Dan Humaniora, 7(2), 378-385.

Yuhana, W. L., \& Nurhikmawati, A. R. (2017). Pemberdayaan Masyarakat Dusun Suweru Dalam Pemasaran Produk Kopi Lokal Melalui Strategi Marketing Mix. Prosiding Seminar Nasional Hasil Pengabdian Kepada Masyarakat Tahun 2017, 52-57. 